\title{
Spatio-temporal distribution and associated factors of home delivery in Ethiopia. Further multilevel and spatial analysis of Ethiopian demographic and health surveys 2005-2016
}

Zemenu Tadesse Tessema ${ }^{1 *}$ (i) and Sofonyas Abebaw Tiruneh ${ }^{2}$

\begin{abstract}
Background: Globally, between 2012 and 2017, 80\% of live births occurred at health facilities assisted by skilled health personnel. In Ethiopia, in 2016 only 26\% of live births attended by skilled health personal. This study aimed to assess the spatial patterns and associated factors of home delivery in Ethiopia using 2005, 2011, and 2016 Ethiopian Demographic and Health Surveys.

Methods: A total of 33,482 women who gave live birth in the 5 years preceding each survey were included for this study. ArcGIS version 10.7 software was used to visualize the spatial distribution of home delivery. The Bernoulli model was applied using Kilduff SaTScan version 9.6 software to identify significant purely spatial clusters for home delivery in Ethiopia. A multilevel logistic regression model was fitted to identify factors associated with home delivery. A $p$-value $<0.05$ was taken to declare statistically significant predictors.

Results: Home delivery was declined from $94.78 \%$ in 2005, 90.05\% in 2011, and 73.44\% in 2016 in Ethiopia. Among the three surveys, consistently high clustering of home delivery was observed in Amhara and Southern Nations Nationalities and People's Regions (SNNPR) of Ethiopia. In spatial scan statistics analysis, a total of 128 clusters (RR $=$ $1.04, P$-value $<0.001)$ in 2005 , and 90 clusters $(R R=1.11, P$-value $<0.001)$ in 2011 , and 55 clusters $(R R=1.29, P$-value $<0.001$ in 2016 significant primary clusters were identified. Educational status of women and husband, religion, distance to the health facility, mobile access, antenatal care visit, birth order, parity, wealth index, residence, and Region were statistically significant predictors of home delivery.

\footnotetext{
* Correspondence: zemenut1979@gamil.com

1 Department of Epidemiology and Biostatics, Institute of Public Health, College of Medicine and Health Sciences, University of Gondar, Gondar, Ethiopia

Full list of author information is available at the end of the article
}

C The Author(s). 2020 Open Access This article is licensed under a Creative Commons Attribution 4.0 International License, which permits use, sharing, adaptation, distribution and reproduction in any medium or format, as long as you give appropriate credit to the original author(s) and the source, provide a link to the Creative Commons licence, and indicate if changes were made. The images or other third party material in this article are included in the article's Creative Commons licence, unless indicated otherwise in a credit line to the material. If material is not included in the article's Creative Commons licence and your intended use is not permitted by statutory regulation or exceeds the permitted use, you will need to obtain permission directly from the copyright holder. To view a copy of this licence, visit http://creativecommons.org/licenses/by/4.0/. The Creative Commons Public Domain Dedication waiver (http://creativecommons.org/publicdomain/zero/1.0/) applies to the data made available in this article, unless otherwise stated in a credit line to the data. 


\begin{abstract}
(Continued from previous page)
Conclusion: The spatial distribution of home delivery among the three consecutive surveys were non-random in Ethiopia. Educational status of women and husband, religion, distance to the health facility, wealth index, residence, parity, mobile access, Region, and antenatal care visit were statistically significant predictors of home delivery in Ethiopia. Therefore, an intervention needs to improve the coverage of antenatal care visit, and health care facilities. Ministry of health and other stakeholders should give special attention to women living in Amhara and SNNPR states of Ethiopia.
\end{abstract}

Keywords: Home delivery, EDHS, Spatial distribution, Ethiopia

\section{Background}

Maternal mortality reduction remains a priority agenda under goal three in the UN Sustainable Development Goals (SDGs) through 2030 [1]. Worldwide, about 295, 000 maternal deaths occurred in 2017 which is $38 \%$ of reduction since the year 2000 an average reduction of just under 3\% per year. Even though a significant decline in maternal mortality in the last 25 years, still maternal mortality is unacceptably high [2]. Every day, about 810 women died from preventable and related causes to pregnancy and childbirth, which is the vast majority of these deaths (94\%) that occurred in low-resource setting countries [3].

Maternal mortality in Ethiopia fell from 1250 deaths per 100,000 livebirths in 1990 to 353 deaths per 100,000 livebirths in 2015 , declined by $71.8 \%$ which is below the target of Millennium Development Goals (MDGs) related to maternal mortality $[4,5]$. Sustainable Development Goal (SDG) goal 3 calls for the ambition of maternal mortality ratio reduction less than 70 per 100 , 000 live births between 2016 to 2030 [6].

About $73 \%$ of all maternal deaths were due to direct obstetric cases and deaths due to indirect causes accounted for $27.5 \%$ of all maternal deaths [7]. Nearly one-quarter of maternal death occurred in the antepartum period, another quarter occurred in the intrapartum and immediate postpartum periods, one-third occurred in the subacute and delayed postpartum periods, and $12 \%$ occurred in the late postpartum period [8].

Globally, between 2012 and 2017 only 80\% of live births occurred at health facilities assisted by skilled health personnel. However, only $59 \%$ of the live births were attended by skilled health personal in the SubSaharan Africa region, where maternal mortality is the highest [9]. Even though, skilled childbirth before, during, and after can save the lives of women, still in Ethiopia, $94.5 \%$ in $2000,93.1 \%$ in $2005,87.9 \%$ in 2011 , and $73.6 \%$ in 2016 birth attended at home which is unacceptable high $[10,11]$.

In Ethiopia, several studies evidenced that, women's low attainment of educational status, cultural factors, communal factors, limited access to health facilities, poor quality of care, lack of transportation, and poor wealth status were the significant factors that lead to low maternal health services utilization [10, 12-14]. So far different studies in Ethiopia done to identify the factors for the choice of place of delivery [15-17]. The spatial distribution of home delivery was unclear in Regions of Ethiopia. Identifying the spatial distribution of home delivery in Ethiopia can help health planners and policymakers for specific interventions to decrease home delivery. This study aimed to assess the spatial distributions of home delivery and associated factors of home delivery in Ethiopia using 2005, 2011, and 2016 Ethiopian Demographic and Health Survey (EDHS) datasets.

\section{Methods}

\section{Study design, period and setting}

A cross-sectional survey study design was conducted in Ethiopia using 2005, 2011, and 2016 EDHS. Ethiopia is located in the Horn of Africa and has 9 Regional states namely Tigray, Afar, Amhara, Oromia, Somali, Benishangul Gumuz, Southern Nations, Nationalities and People's Region (SNNPR), Gambella, and Harari Regional states and two administrative cities namely Addis Ababa and Dire Dawa.

\section{Source and study population}

The source population was all reproductive age group women (15-49) in Ethiopia. The study population was women who gave birth in the last 5 years preceding each survey for the recent birth.

\section{Sample size and sampling procedure}

A total of 33,482 women (10,721 women in 2005, 11,872 women in 2011, and 10,889 women in 2016) were included in this study. Weighted values were used to restore the representativeness of the sample data. Sample weights were calculated in each children's record (KR) EDHS datasets. The survey covered all nine regions and the two city administrations of Ethiopia. Participants were selected based on a stratified two-stage cluster sampling technique in each survey year $(2005,2011$, and 2016). After excluding clusters with zero coordinates and no birth records, a total of 527 clusters in 2005, 571 clusters in 2011, and 622 clusters in 2016 were included. 
The detailed sampling procedure was available in each EDHS reports from Measure DHS website (www. dhsprogram.com).

\section{Data collection tools and procedures}

The data obtained from the Demographic and Health Surveys (DHS) Program by requesting for this work and accessed www.dhsprogram.com website. Ethiopian Demographic and Health Survey data collected by twostage stratified sampling. Each region of the country was stratified into urban and rural areas.

\section{Variables}

\section{Outcome variable}

The outcome variable taken as binary response woman gave birth at home and others home coded as "1" which is home delivery, and women gave birth different governmental health facilities, private health facilities, and non-governmental health facilities coded as " 0 " which is health facility delivery.

\section{Independent variables}

From the EDHS dataset all sociodemographic and obstetric characteristics (individual and community level) taken as independent variables in the three-consecutive survey.

\section{Data management and analysis}

The data cleaned by STATA version 14.1 software and Microsoft excel. Sample weighting was done before further analysis.

\section{Spatial autocorrelation}

We used Arc GIS 10.7 software for spatial autocorrelation and detection of hot spot areas. Spatial autocorrelation (Global Moran's I) statistic measure was used to assess whether home delivery was dispersed, clustered, or randomly distributed in Ethiopia. Moran's I values close to -1 indicates dispersed home delivery, close to +1 indicates clustered, and if Moran's I value zero indicates randomly distributed [18].

\section{Hot spot analysis}

The proportion of home delivery in each cluster was taken as an input to analyze the hotspot analysis. Hot Spot Analysis (Getis-Ord Gi* statistic) of the z-scores and significant $p$-values tells the features with either hot spot or cold spot values for the clusters spatially. The hot spot areas indicated that there was a high proportion of home delivery and the cold spot indicated that there was a low proportion of home delivery. The maximum peak distance in which spatial dependency pronounced at $151.37 \mathrm{Km}$ in $2016,148.13 \mathrm{Km}$ in 2011 , and $193.9 \mathrm{~km}$ in 2005 EDHSs.

\section{Spatial interpolation}

The spatial interpolation technique is used to predict home delivery for unsampled areas based on sampled clusters. For the prediction of unsampled clusters, we used geostatistical ordinary Kriging spatial interpolation technique using ArcGIS 10.7 software. In each EDHS survey year, home delivery is known for all enumeration areas, but home delivery for other unselected locations in Ethiopia is also of interest.

\section{Spatial scan statistics}

We employed Bernoulli based model spatial scan statistics to determine the geographical locations of statistically significant clusters for home delivery using Kuldorff's SaTScan version 9.6 software [19]. The scanning window that moves across the study area in which women gave birth at home were taken as cases and those women who gave birth at health facility taken as controls to fit the Bernoulli model. The default maximum spatial cluster size of $<50 \%$ of the population was used as an upper limit, allowing both small and large clusters to be detected, and ignored clusters that contained more than the maximum limit with the circular shape of the window. Most likely clusters were identified using $p$-values and likelihood ratio tests based on 999 Monte Carlo replications.

\section{Model building}

We fit four models, the null model without predictors, the model I with only individual-level variables, model II with only community-level variables, and model III both individual-level and community-level variables. These models were fitted using a STATA command $x$ tmelogit. For model comparison, we used the Log-Likelihood Ratio (LLR). The highest log-likelihood wins the best-fitted model.

\section{Parameter estimation methods}

In the multilevel multivariable logistic regression model, fixed effect estimates measure the association between the odds of home delivery of individual and community level factors with a 95\% confidence interval. Univariate analysis was carried out. A $P$-value less than or equal to 0.25 was taken as the candidate variable for the multivariable analysis. Adjusted Odds Ratio (AOR) with 95\% $\mathrm{CI}$ and $\mathrm{P}$-value less than 0.05 were reported as a significant factor that affects home delivery. Multicollinearity was checked using the Variance Inflation Factor (VIF). VIF less than $10 \%$ was taken as no multicollinearity.

The random effect measures variation of home delivery across clusters expressed by Intraclass Correlation (ICC) which quantifies the degree of heterogeneity of home delivery between clusters, Percentage Change in Variance (PCV) the proportion of the total observed 
individual variation of home delivery that is attributable to between cluster variations, and Median Odds Ratio (MOR) median value of the odds ratio between the cluster at high-risk home delivery and cluster at lower risk of home delivery when randomly picking out two clusters.

\section{Results}

\section{Background characteristics of individual women}

A total of 33,482 women $(10,721$ in $2005,11,872$ in 2011, and 10, 889 in 2016) were included for this study. Overall, 94.78, 90.05, and 73.44\% of women gave birth at home in 2005, 2011, and 2016 EDHSs respectively. From the three consecutive surveys, more than $60 \%$ of the mothers were in the age group of 20-34 years and had the same mean \pm SD age of $29 \pm 6.6$ years. Among the three surveys, a significant number $(48 \%)$ of the female household head was observed in the 2011 EDHS survey. All most all (>90\%), of the women were married in 5 years preceding the survey in three consecutive surveys. The educational status of the women was 79, 69, and $66 \%$ were unable to read and write in each survey year respectively. As well, 31, 47, and 56\% of women were had not any work in the consecutive surveys respectively. In the EDHS 2016 survey, personal mobile and health insurance status were interviewed but not in EDHS 2005 and 2011. In 5 years, preceding the survey $16.4 \%$ of women were had personal mobile and $3.46 \%$ of women were insured for health insurance (Table 1). Despite the high prevalence of home delivery in Ethiopia, all regions registered in the decreasing trend from 2005 to 2016 (Fig. 1).

\section{Characteristics of the cluster}

The unit of analysis for the community factors on home delivery was clusters. In EDHS 2016, 645 clusters were selected; from these 643 clusters were eligible in which the women give birth preceding 5 years the survey. Among the total number of clusters, 69\% were rural in residence and almost half (49\%) of the clusters were had a big problem accessing any health institution. Regarding the aggregate community, ANC utilization rate half of the clusters were had low community utilization. From the total of clusters, half of them were had low community women educational attainment and high community poverty status (Table 2 ).

Spatio-temporal distribution of home delivery in Ethiopia The spatial distribution of home delivery in Ethiopia was non-random among the three consecutive surveys. The global Moran's I value was 0.12 ( $P$-value < $0.001)$ in $2005,0.59(P$-value $<0.001)$ in 2011 , and 0.44 ( $P$-value $<0.001)$ in 2016 Ethiopian Demographic and health surveys.

\section{Hot spot analysis of the three surveys}

The spatial distribution of home delivery in Ethiopia was different in the three survey years. In EDHS 2005, a high proportion of home delivery was detected mainly at Amhara and SNNPR regional states of Ethiopia. In EDHS 2011, high clustering of home delivery detected in most parts of Tigray, Amhara, Afar, Benishangul and SNNPR, and western part of the Oromia region of Ethiopia. Furthermore, in EDHS 2016 high proportion of home delivery detected in the southern part of Afar, Southeastern part of Amhara, SNNPR, Benishangul Gumuz, and Somali region of Ethiopia (Fig. 2).

\section{Spatial scan statistics analysis of the three survey years}

As shown in Fig. 3 below, the red window indicates the identified significant clusters inside the window. In spatial scan statistics, a total of 158 most likely clusters were identified in EDHS 2005 survey. The most likely clusters of home delivery were detected in most parts of Amhara, southwestern part of Tigray, SNNPR, and Eastern part of the Benishangul Gumuz region of Ethiopia. Among the most likely clusters, 128 of them were primary clusters which are located at $11.586460 \mathrm{~N}$ and $37.367962 \mathrm{E}$ with $290.16 \mathrm{~km}$ radius. In EDHS 2005, mothers live in the primary cluster were $4 \%$ more likely to give birth at home than outside the window (Relative risk $(\mathrm{RR})=1.04$ and Log-Likelihood ratio $(\mathrm{LLR})=45.75$, $P$-value $<0.001)$.

In EDHS 2011, a total of 127 most likely clusters were identified in spatial scan statistics which is located at Southeastern Oromia and Sothern part of the Somali region of Ethiopia. Among the most likely cluster, 90 of them were primary clusters located at $5.842888 \mathrm{~N}$ and $42.105068 \mathrm{E}$ with $396.38 \mathrm{~km}$ radius. Mothers live in the primary cluster were $11 \%$ more likely to deliver at home as compared to outside the window $(R R=1.11, L L R=$ 161.45, $P$-value < 0.001).

Furthermore, in the 2016 EDHS survey, 70 most likely clusters were detected spatially. The most likely clusters of home delivery were detected in southeastern Oromia and the western Somali region of Ethiopia. From the most likely clusters, 55 of them were primary clusters located at $5.330795 \mathrm{~N}$ and $41.837597 \mathrm{E}$ with $400.35 \mathrm{~km}$ radius. Mothers who live in the primary clusters were $29 \%$ more likely to give birth at home as compared to outside the window $(\mathrm{RR}=1.29, \mathrm{LLR}=210.89, P$-value $<0.001)$ (Fig. 3).

\section{Prevalence of home delivery in Ethiopia in the three EDHS surveys}

Based on geostatistical Kriging analysis, in 2005 EDHS exclusively Dira Dawa, Harari, and Addis Ababa had a prevalence of home delivery less than 73\%. In 2011 EDHS survey still, there is no significant difference in- 
Table 1 Sociodemographic characteristics of women who had a live birth in the five years preceding the survey from EDHS 2005, 2011, and 2016 in Ethiopia

\begin{tabular}{|c|c|c|c|c|}
\hline \multirow[t]{3}{*}{ Characteristics } & & \multicolumn{3}{|l|}{ EDHS years } \\
\hline & & \multirow{2}{*}{$\begin{array}{l}2005 \\
\text { Frequency (\%) }\end{array}$} & \multirow{2}{*}{$\begin{array}{l}2011 \\
\text { Frequency (\%) }\end{array}$} & \multirow{2}{*}{$\begin{array}{l}2016 \\
\text { Frequency (\%) }\end{array}$} \\
\hline & & & & \\
\hline \multirow[t]{4}{*}{ Women age } & $<20$ Years & $1315(12.26)$ & $1132(9.53)$ & $851(7.81)$ \\
\hline & 20-34 years & $6655(62.07)$ & 7861 (66.22) & 7337 (67.38) \\
\hline & 35-49 Years & $2752(25.67)$ & $2879(24.25)$ & $2701(24.80)$ \\
\hline & Mean \pm SD & $29.01 \pm 6.94$ & $29.04 \pm 6.63$ & $29.57 \pm 6.60$ \\
\hline \multirow[t]{2}{*}{ Household head } & Male & $9558(89.15)$ & $6168(51.95)$ & 9371 (86.06) \\
\hline & Female & $1163(10.85)$ & $5704(48.05)$ & $1518(13.94)$ \\
\hline \multirow[t]{3}{*}{ Marital status } & Not having partner & $488(4.50)$ & $721(6.07) 6.07$ & $681(6.25)$ \\
\hline & Had partner & $10,233(95.50)$ & 11,151 (93.93) 100.00 & $10,208(93.75)$ \\
\hline & Total & $10,721(100)$ & $11,872(100)$ & $10,889(100)$ \\
\hline \multirow[t]{4}{*}{ Religion } & Orthodox & $4543(42.37)$ & 4519 (38.06) 38.06 & 3718 (34.14) \\
\hline & Muslim & $3752(35.00)$ & 4214 (35.49) 73.56 & $4519(41.50)$ \\
\hline & Protestant & $2138(19.91)$ & 2758 (23.23) 96.78 & $2297(21.09)$ \\
\hline & Others & $286(2.68)$ & $382(3.22) 100.00$ & $355(3.26)$ \\
\hline \multirow[t]{2}{*}{ Residence } & Urban & $760(7.09)$ & 1528 (12.87) 12.87 & $1213(11.14)$ \\
\hline & Rural & 9961 (92.91) & $10,344(87.13)$ & $9676(88.86)$ \\
\hline \multirow[t]{11}{*}{ Region } & Tigray & $684(6.39)$ & $753(6.34)$ & $701(6.44)$ \\
\hline & Afar & $104(0.97)$ & $121(1.02)$ & $114(1.05)$ \\
\hline & Amhara & $2571(23.99)$ & 2656 (22.37) 29.74 & $2041(18.74)$ \\
\hline & Oromia & 4255 (39.69) & 5014 (42.23) 71.97 & $4813(44.20)$ \\
\hline & Somalia & $455(4.24)$ & $365(3.07)$ & $508(4.66)$ \\
\hline & Benishangul Gumuz & $83(.78)$ & $140(1.18)$ & $120(1.11)$ \\
\hline & SNNP & $2338(21.81)$ & $2494(21.01)$ & $2250(20.67)$ \\
\hline & Gambela & $29(.27)$ & $40(0.34)$ & $27(0.24)$ \\
\hline & Harari & 20(.19) & $29(0.24)$ & $26(0.24)$ \\
\hline & Addis Ababa & $141(1.32)$ & $222(1.87)$ & $243(2.33)$ \\
\hline & Dire Dawa & $36(.34)$ & $39(0.33)$ & $46(0.42)$ \\
\hline \multirow[t]{4}{*}{ Women education } & Unable to read and write & $8502(79.31)$ & $8227(69.30) 69.30$ & $7201(66.13)$ \\
\hline & Primary education & $1772(16.53)$ & $3211(27.05)$ & $2904(26.67)$ \\
\hline & Secondary education & 409 (3.79) & $266(2.24)$ & $510(4.68)$ \\
\hline & Higher education & $40(.38)$ & $168(1.42)$ & $274(2.52)$ \\
\hline \multirow[t]{4}{*}{ Husband education } & Unable to read and write & $6308(59.03)$ & $5966(50.60)$ & $5018(48.57)$ \\
\hline & Primary education & $3245(30.37)$ & $4867(41.26)$ & $4051(39.21)$ \\
\hline & Secondary education & $1023(9.58)$ & $584(4.95) 6.81$ & $790(7.65)$ \\
\hline & Higher education & $109(1.01)$ & $376(3.19)$ & $471(4.56)$ \\
\hline \multirow[t]{2}{*}{ Women occupation } & Not working & $7623(30.71)$ & $5597(47.14)$ & $6057(55.62)$ \\
\hline & Working & $3098(28.89)$ & $6275(52.86)$ & $4832(44.38)$ \\
\hline \multirow[t]{2}{*}{ Husband occupation } & Not working & $215(2.00)$ & $158(1.33)$ & $6199(56.93)$ \\
\hline & Working & $10,506(98.00)$ & $11,714(98.67)$ & $4690(43.07)$ \\
\hline \multirow[t]{2}{*}{ Distance to health facility } & Big problem & $6597(60.58)$ & $8956(75.43)$ & $6597(60.58)$ \\
\hline & Not a big problem & $4292(39.42)$ & $2916(24.57)$ & $4292(39.42)$ \\
\hline Media exposure & No media exposure & 7347 (68.41) & 8956 (75.43) & 7347 (68.41) \\
\hline
\end{tabular}


Table 1 Sociodemographic characteristics of women who had a live birth in the five years preceding the survey from EDHS 2005, 2011, and 2016 in Ethiopia (Continued)

\begin{tabular}{|c|c|c|c|c|}
\hline \multirow[t]{3}{*}{ Characteristics } & & \multicolumn{3}{|l|}{ EDHS years } \\
\hline & & \multirow{2}{*}{$\begin{array}{l}2005 \\
\text { Frequency (\%) }\end{array}$} & \multirow{2}{*}{$\begin{array}{l}2011 \\
\text { Frequency (\%) }\end{array}$} & \multirow{2}{*}{$\begin{array}{l}2016 \\
\text { Frequency (\%) }\end{array}$} \\
\hline & & & & \\
\hline & Has media exposure & $3392(31.59)$ & $2916(24.57)$ & $3392(31.59)$ \\
\hline \multirow[t]{2}{*}{ Had mobile } & No & NA & NA & 9103 (83.60) 83.60 \\
\hline & Yes & NA & NA & $1786(16.40)$ \\
\hline \multirow[t]{2}{*}{ Insurance } & Not insured & NA & NA & $10,512(96.54)$ \\
\hline & Insured & NA & NA & $377(3.46)$ \\
\hline \multirow[t]{3}{*}{ Had ANC } & No & $5041(71.86)$ & $4543(57.45)$ & $2792(37.42)$ \\
\hline & Yes & $1973(28.14)$ & $3365(42.55)$ & $4670(62.58)$ \\
\hline & Total & $7014(100)$ & 7908 (1000) & $7462(100)$ \\
\hline \multirow[t]{3}{*}{ Birth order } & 1 & $2030(18.65)$ & $2261(19.05)$ & $2030(18.65)$ \\
\hline & $2-4$ & $4660(42.80)$ & $5179(43.62)$ & $4661(42.80)$ \\
\hline & $\geq 5$ & $4197(35.55)$ & $4432(37.33)$ & 4198 (38.55) \\
\hline \multirow[t]{3}{*}{ Parity } & $\leq 2$ & $3135(28.80)$ & $3469(29.22)$ & $3136(28.80)$ \\
\hline & $2-5$ & $4319(39.67)$ & $4710(39.67)$ & $4319(39.67)$ \\
\hline & $\geq 5^{+}$ & $3433(31.53)$ & $3693(31.11)$ & 3434 (31.53) \\
\hline \multirow[t]{3}{*}{ Wealth index } & Poor & $5091(46.67)$ & $5368(45.22)$ & $5091(46.76)$ \\
\hline & Middle & $2243(20.60)$ & $2437(20.53)$ & $2243(20.60)$ \\
\hline & Richer & 3554 (32.64) & $4067(34.26)$ & 3555 (32.64) \\
\hline \multirow[t]{2}{*}{ Place of delivery } & Health institution & $560(5.22)$ & 1180 (9.95) & $2891(26.56)$ \\
\hline & Home & 10,161 (94.78) & $10.691(90.05)$ & 7997 (73.44) \\
\hline Total & & $10,721(100)$ & $11,872(100)$ & $10,889(100)$ \\
\hline
\end{tabular}

NB: NA = Indicates data not available in that EDHS year

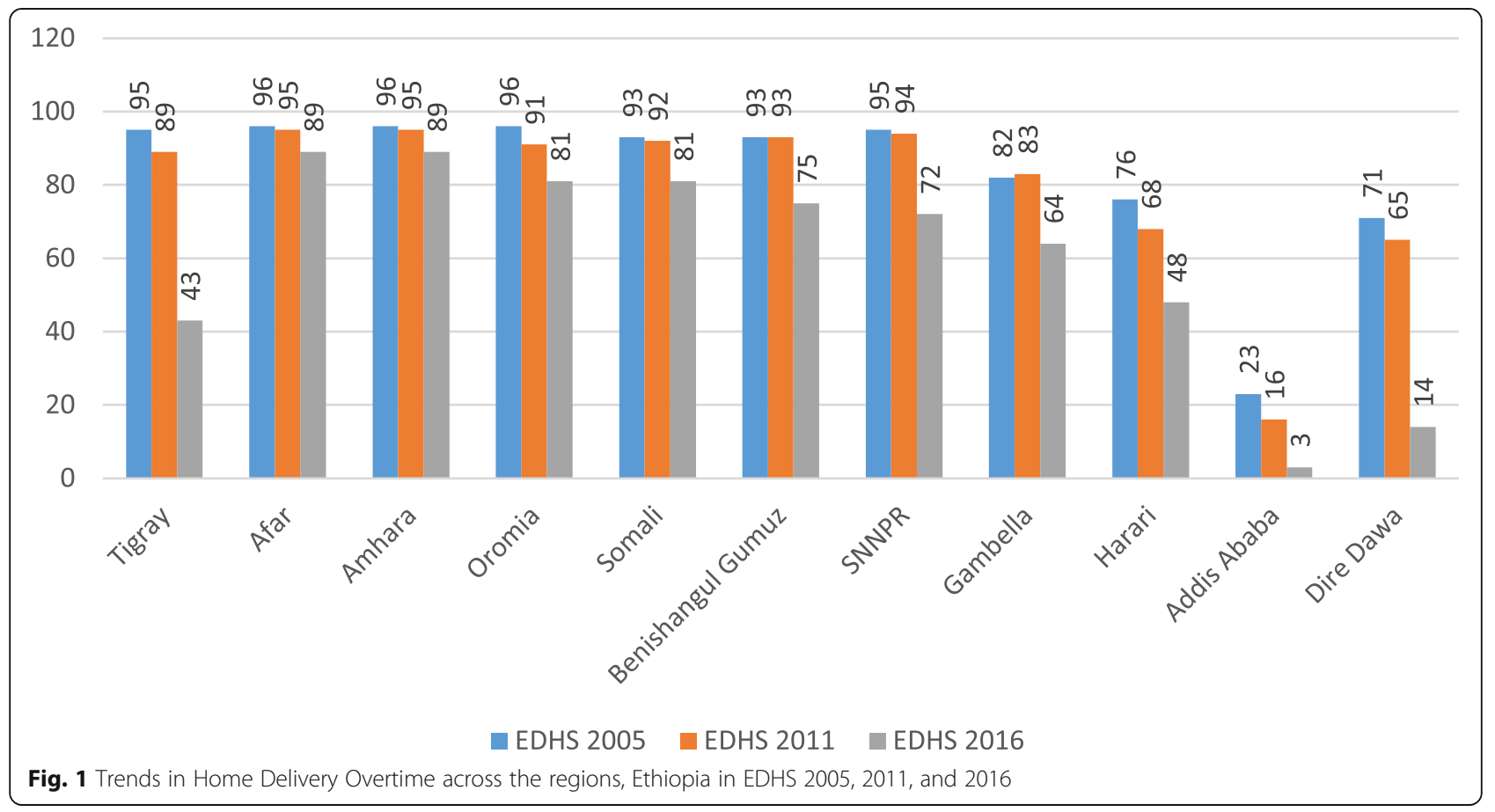


Table 2 Characteristics of clusters in EDHS 2016

\begin{tabular}{|c|c|c|c|}
\hline \multicolumn{2}{|l|}{ Community-level characteristics } & \multirow{2}{*}{$\begin{array}{l}\text { Frequency } \\
441\end{array}$} & \multirow{2}{*}{$\begin{array}{l}\text { Percent }(\%) \\
68.68\end{array}$} \\
\hline Residence & Rural & & \\
\hline & Urban & 202 & 31.32 \\
\hline \multirow[t]{11}{*}{ Region } & Tigray & 63 & 9.80 \\
\hline & Afar & 53 & 8.24 \\
\hline & Amhara & 71 & 11.04 \\
\hline & Oromia & 74 & 11.51 \\
\hline & Somali & 67 & 10.42 \\
\hline & Benishangul & 50 & 7.78 \\
\hline & SNNPR & 71 & 11.04 \\
\hline & Gambela & 50 & 7.78 \\
\hline & Harari & 44 & 6.84 \\
\hline & Addis Ababa & 56 & 8.71 \\
\hline & Dire Dawa & 44 & 6.84 \\
\hline \multirow[t]{2}{*}{ Community ANC utilization rate } & Low & 320 & 49.77 \\
\hline & High & 323 & 50.23 \\
\hline \multirow[t]{2}{*}{ Community distance to the health facility } & Big problem & 314 & 48.83 \\
\hline & Not a big problem & 329 & 51.17 \\
\hline \multirow[t]{2}{*}{ Community media exposure } & Low & 321 & 49.92 \\
\hline & High & 322 & 50.08 \\
\hline \multirow[t]{2}{*}{ Community poverty status } & High & 319 & 49.61 \\
\hline & Low & 324 & 50.39 \\
\hline \multirow[t]{2}{*}{ Community-women educational attainment } & Low & 318 & 49.46 \\
\hline & High & 325 & 50.54 \\
\hline Total & & 643 & 100 \\
\hline
\end{tabular}

home delivery reduction compared to 2005 EDHS across the region of Ethiopia. In the EDHS 2016 survey, Tigray, Addis Ababa, some parts of Oromia, Dire Dawa, and Gambela region significantly decreased home delivery in Ethiopia as compared to the other region (Fig. 4).

\section{Multilevel analysis (random effect analysis)}

A Home delivery prevalence rate was not similarly distributed across the communities. About $67.32 \%$ of the variance in the odds of home delivery in women could be attributed to community-level factors, as calculated by the ICC based on estimated intercept component variance and the variation was statistically significant $(p-$ value $<0.001)$. After adjusting for individual-level and community-level factors, the variation in-home delivery across communities remained statistically significant. About $89 \%$ of the odds of home delivery variation across communities was observed in the full model (Model 4). Moreover, the MOR indicated that home delivery was attributed to community-level factors. The MOR for home delivery was 12.17 in the empty model (Model 1); this showed that there was variation between communities (clustering) since MOR was 12.17 times higher than the reference $(\mathrm{MOR}=1)$. The unexplained community variation in-home delivery decreased to MOR of 2.54 when all factors were added to the null model (empty model). This indicates that when all factors are included, the effect of clustering is still statistically significant in the full model.

\section{Individual-level predictors for home delivery}

This study evidenced that on multivariable multilevel logistic regression analysis, individual-level factors such as religion, ANC visit, wealth index, birth order, parity, distance from the health facility, insurance, and mobile access were statistically significant factors for home delivery.

Keeping all individual and community level factors constant, the odds of giving birth at home for protestant in religion followers was 1.62 times higher than orthodox followers $(\mathrm{AOR}=1.62, \quad(95 \% \mathrm{CI}, 1.15,2.28)$ ). Mothers who had personal mobile were $40 \%$ less likely gave birth at home than those who had no personal mobile $(\mathrm{AOR}=0.60,(95 \% \mathrm{CI}, 0.48,0.76))$. Women who had at least one ANC visit at the health facility were $82 \%$ less likely to deliver at home than those who had no ANC 


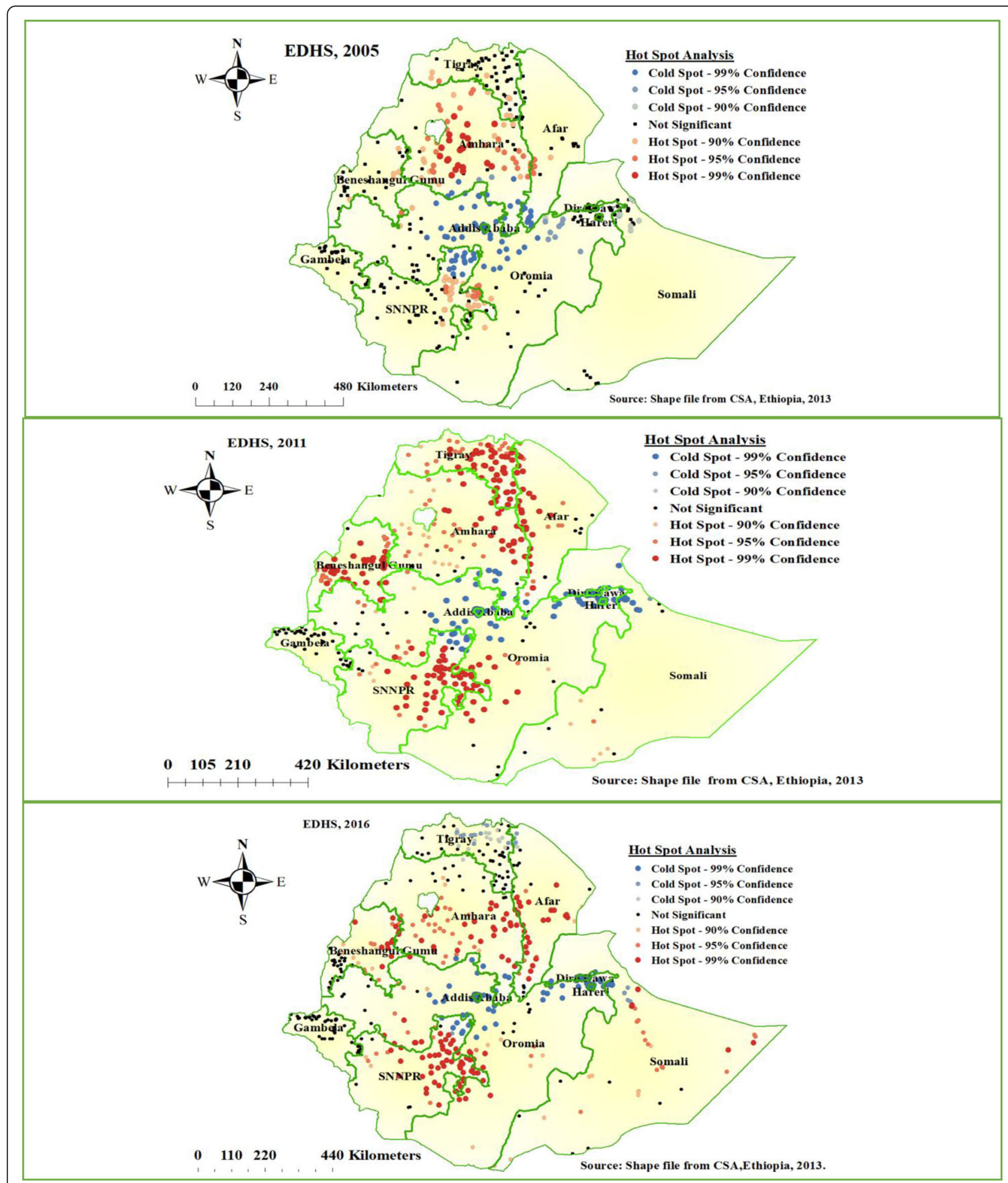

Fig. 2 Hot spot analysis of home delivery in Ethiopia, EDHS 2005 to 2016 (Source: Shape file from Ethiopia Central Statistical Agency (CSA), 2013)

visit $(\mathrm{AOR}=0.18,(95 \% \mathrm{CI}, 0.14,0.22))$. The odds of giving birth at home among women who had 2-5 and more than five birth order were 78 and $87 \%$ than birth order less than 2 respectively $(\mathrm{AOR}=1.78,(95 \% \mathrm{CI}, 1.36$,
2.34), $\quad \mathrm{AOR}=1.87, \quad(95 \% \mathrm{CI}, 1.27,2.76))$. Multiparous women (para 2-5) had high odds of giving birth at home by $37 \%$ as compared to para II women (AOR $=1.37,95 \%$ $\mathrm{CI}, 1.08,1.74)$ ). Furthermore, mothers rich in their 


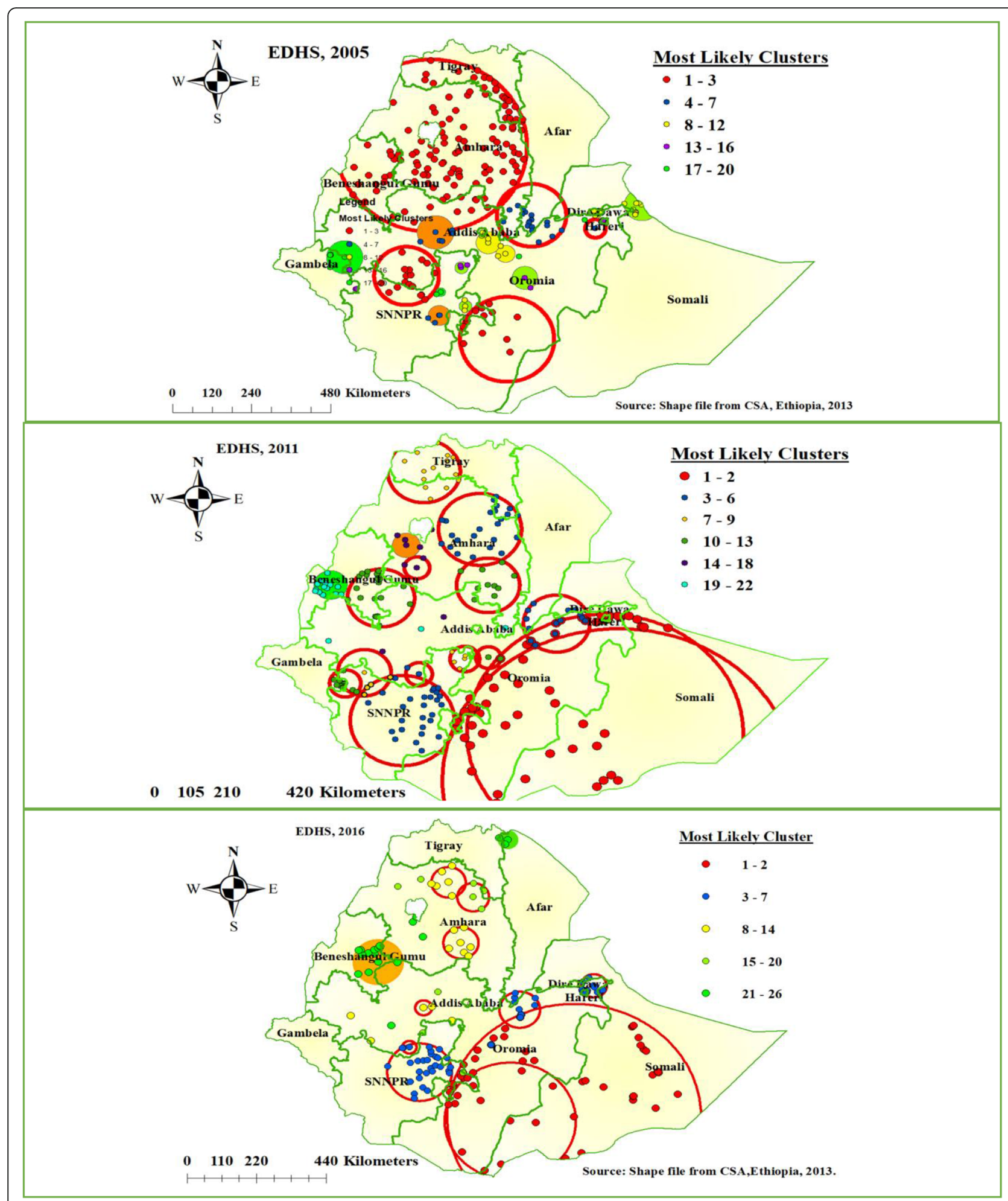

Fig. 3 SaTScan scan statistics analysis of home delivery in Ethiopia, EDHS 2005 to 2016 (Source: Shape file from Ethiopia Central Statistical Agency (CSA), 2013) 


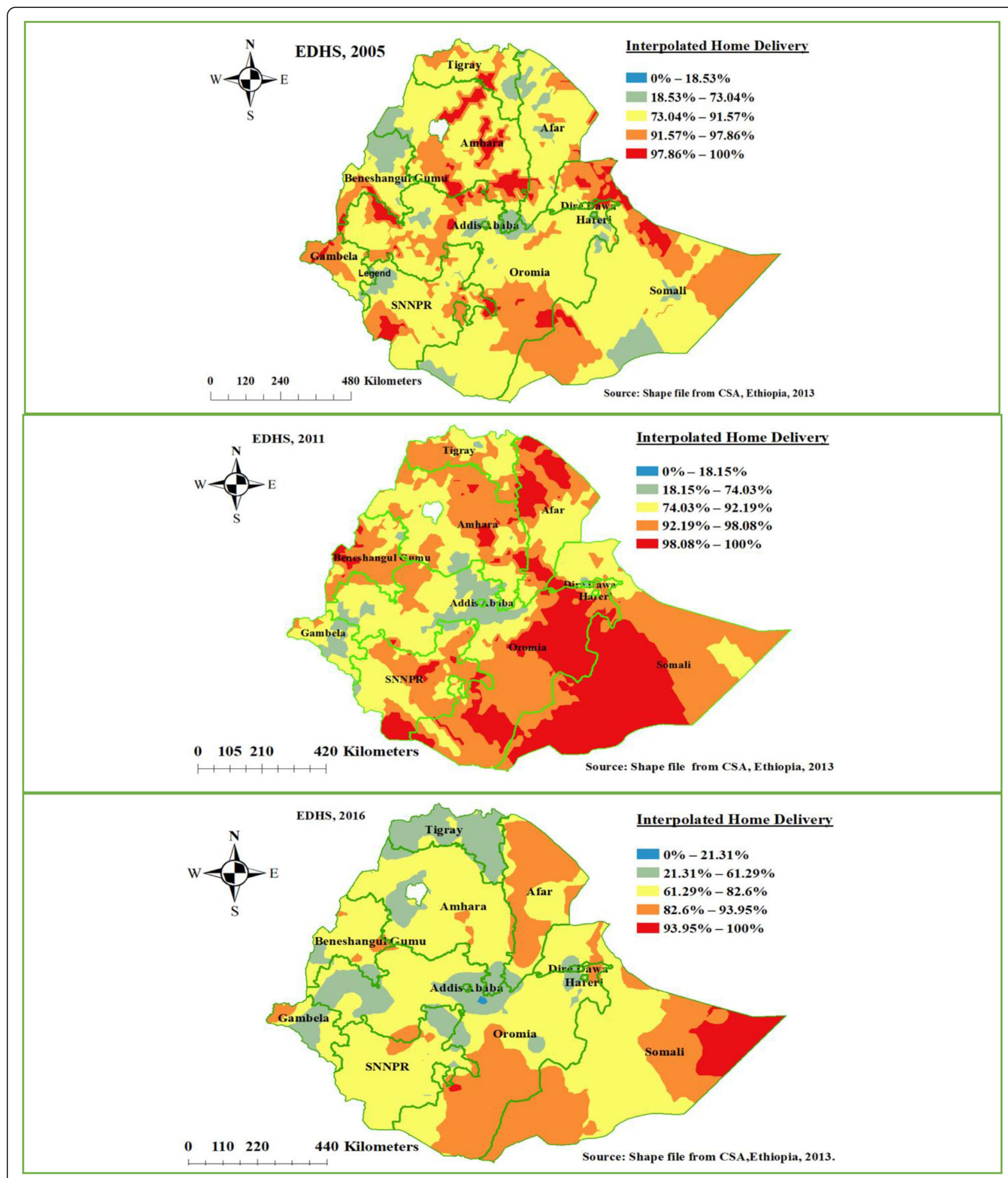

Fig. 4 Ordinary Kriging interpolation of home delivery in Ethiopia, EDHS 2005 to 2016 (Source: Shape file from Ethiopia Central Statistical Agency (CSA), 2013)

wealth were $22 \%$ less likely to deliver at home as compared to poor wealth status $(\mathrm{AOR}=0.78$, $(95 \% \mathrm{CI}$, $0.61,0.99))$.
Community-level predictors for home delivery

In the multivariable multilevel logistic regression model residence, region, community ANC utilization rate, 
community women education, and distance to any health institution were significantly associated with community-level factors for place delivery.

Keeping all individual and community level factors constant, women in rural clusters were three times more likely to give birth at home than women in urban clusters $(\mathrm{AOR}=2.92$, $(95 \%, 1.99,4.29))$. Regarding regions, women live in Afar, Amhara, and Somali had high odds of giving birth at home as compared to Addis Ababa $(\mathrm{AOR}=11.03,(95 \% \mathrm{CI}, 4.29,28.41), \mathrm{AOR}=6.39,(95 \%$ $\mathrm{CI}, 2.60,15.70), \mathrm{AOR}=6.02,(95 \% \mathrm{CI}<2.41,15.06))$. Women live in Tigray and Dire Dawa were no significant difference in the place of delivery as compared to Addis Ababa $(\mathrm{AOR}=1.46,(95 \% \mathrm{CI}, 0.59,3.60)$, AOR = 2.01, (95\% CI, 0.77, 5.20)). Women who live in a high community ANC utilization were 50\% less likely to give birth at home than in low community ANC utilization in 5 years preceding the survey $(\mathrm{AOR}=0.50,(95 \% \mathrm{CI}$, $0.39,0.65)$ ). Women in a cluster had no problem accessing any health institution were less likely to deliver at home by $29 \%$ those women had a problem accessing health facilities (AOR $=0.69$, (95\%CI, 0.53, 0.90)). Furthermore, high women education status in the cluster (community) was $28 \%$ less likely deliver at home than low women education attainment at the cluster in 5 years preceding the survey (AOR $=0.78,(95 \% \mathrm{CI}, 0.60$, 0.99)) (Table 3).

NB: * = Significant at $P$-value $<0.05, * *=$ Significant at $P$-value, $0.01,{ }^{* * * *}=$ Significant at $P$-value $0.001, C I$ Confidence Interval, $A O R$ Adjusted Odds Ratio

\section{Discussion}

This study revealed that $73.44 \%$ (95\% CI; 72.60, 74.26) of women deliver at home preceding the survey period. This finding was consistence with the study done Southeast Ethiopia (73.6\%) [20], whereas it is higher than the study done at Afar, Ethiopia (65\%), South Ethiopia (62.2\%), Arba Minch town Ethiopia (33.2\%), Akordet town, Eritrea (18\%), the urban community at Nigeria (35\%), and Ghana (51.2\%) [21-26]. The discrepancy might be the study area, setting deference, cultural attitude for health facility delivery, and infrastructure difference (access to the health facility, roads...). In this study, most of the women live in rural areas, which results in a higher prevalence of home delivery. This finding was lower than the 2011 EDHS report (90\%), and a study conducted at the rural community of Nigeria (95.3\%) $[24,27]$. The possible reason might be time difference, and multidimensional strategies are taken to enhance health facility delivery in Ethiopia through health extension workers.

The spatial distribution of home delivery in Ethiopia was non-random in the three successive EDHSs. The spatial distribution of home delivery consistently high in
Amhara, and SNNPR regional states of Ethiopia the possible reason might be behavioral, cultural, and health infrastructure inaccessibility. In 2005 EDHS, spatial scan statistics identified the most likely significant cluster at Southwestern Tigray, Amhara, Northern Benishangul Gumuz, and some part of Oromia regional state of Ethiopia. In 2011 and 2016 EDHS most likely significant cluster located at Somali and Oromia regional states of Ethiopia. The possible geographical variation of home delivery in the regions of Ethiopia might be sociodemographic factors, cultural behaviors to health facility delivery, and different infrastructure across the regions of Ethiopia.

Educated women both at the individual and community level were more likely to deliver at the health facility as compared to non-educated women. This finding supported by different studies conducted in Ethiopia [23, 28-30], Sub-Saharan Africa countries, Nepal, and Ghana $[26,31,32]$. Attaining higher education among women can influence the choice of place of delivery in different ways. Educated women would know the benefit of health facility delivery and the danger of giving birth at home through reading newspapers, mass media, and from different social media. Overall, educated women had good health-seeking behavior and the use of health services. Similarly, educated husbands influence the choice of place of delivery, which might be educated husbands would decide on the place of birth for their wives. This finding supported by other studies conducted in Southeast Ethiopia and Ghana [20,26].

This study evidenced that nearby access to a health facility with a reasonable distance (less than $1 \mathrm{~km}$ ) positively affects the choice of place of delivery at the individual and community level. Similar findings reported from different studies in Ethiopia, Ghana, and Nigeria [24, 26, 28, 30,33]. In line with this finding, this study also evidenced that mothers living in a rural area of Ethiopia were more likely to give birth at home than those living in urban, which is also supported by other studies [30, 32, 34]. The possible justification is the fact that mothers living in a rural area far from the health facility. Ethiopia works to expand primary health care facilities through health extension workers at the health post level. Even though accessing services close to the community, still the topography and infrastructure of Ethiopia are difficult to reach for ambulance service. Therefore, mothers living in a rural area didn't reach the health facility on time for delivery and would influence by the first (mother decision to seek delivery care) and second (reach on time to a health facility) delays for health facility delivery [35].

Another predictor variable that affects the choice of place of delivery was a mobile phone. Women who had a mobile phone or access to mobile phones from their 
Table 3 Multivariable multilevel logistic regression analysis of both individual and community-level factors associated with Home Delivery in Ethiopia, EDHS 2016

\begin{tabular}{|c|c|c|c|c|}
\hline \multirow{3}{*}{$\begin{array}{l}\text { Individual and community- } \\
\text { level variables }\end{array}$} & \multicolumn{4}{|l|}{ Models } \\
\hline & Null model & Model I & Model II & Model III \\
\hline & AOR $(95 \% \mathrm{Cl})$ & AOR $(95 \% \mathrm{Cl})$ & AOR $(95 \% \mathrm{Cl})$ & AOR $(95 \% \mathrm{Cl})$ \\
\hline \multicolumn{5}{|l|}{ Mother's age } \\
\hline$<20$ Years & & 1 & & 1 \\
\hline 20-34 years & & $0.79(0.59,1.05)$ & & $0.90(0.67,1.20)$ \\
\hline 35-49 Years & & $0.70(0.49,1.01)$ & & $0.91(0.63,1.31)$ \\
\hline \multicolumn{5}{|l|}{ Household head } \\
\hline Male & & 1 & & 1 \\
\hline Female & & $0.89(0.72,1.11)$ & & $0.89(0.72,1.11)$ \\
\hline \multicolumn{5}{|l|}{ Marital status } \\
\hline Not having a partner & & 1 & & 1 \\
\hline Had a partner & & $1.44(0.71,2.90)$ & & $1.10(0.54,2.25)$ \\
\hline \multicolumn{5}{|l|}{ Religion } \\
\hline Orthodox & & 1 & & 1 \\
\hline Muslim & & $1.52(1.19,1.95)$ & & $0.93(0.68,1.25)$ \\
\hline Protestant & & $2.26(1.68,3.02)$ & & $1.62(1.15,2.28) *$ \\
\hline Others & & $2.21(1.15,4.24)$ & & $1.48(0.77,2.84)$ \\
\hline \multicolumn{5}{|l|}{ Women education } \\
\hline Unable to read and write & & 1 & & 1 \\
\hline Primary education & & $0.69(0.57,0.83)$ & & $0.75(0.62,0.90) * * *$ \\
\hline Secondary education & & $0.39(0.27,0.56)$ & & $0.50(0.34,0.72) * * *$ \\
\hline Higher education & & $0.25(0.13,0.47)$ & & $0.34(0.18,0.66) * * *$ \\
\hline \multicolumn{5}{|l|}{ Husband education } \\
\hline Unable to read and write & & 1 & & 1 \\
\hline Primary education & & $0.74(0.61,0.89)$ & & $0.83(0.69,0.99) *$ \\
\hline Secondary education & & $0.44(0.53,0.59)$ & & $0.53(0.39,0.70) * * *$ \\
\hline Higher education & & $0.48(0.33,0.69)$ & & $0.56(0.38,0.81)^{* * *}$ \\
\hline \multicolumn{5}{|l|}{ Women occupation } \\
\hline Not working & & 1 & & 1 \\
\hline Working & & $1.31(0.72,2.40)$ & & $1.47(0.80,2.69)$ \\
\hline \multicolumn{5}{|l|}{ Husband occupation } \\
\hline Not working & & 1 & & 1 \\
\hline Working & & $0.78(0.42,1.42)$ & & $0.69(0.38,1.26)$ \\
\hline \multicolumn{5}{|l|}{ Distance to any health facility } \\
\hline Big problem & & 1 & & 1 \\
\hline Not a big problem & & $0.64(0.54,0.75)$ & & $0.79(0.66,0.94) * *$ \\
\hline \multicolumn{5}{|l|}{ Media exposure } \\
\hline No media exposure & & 1 & & 1 \\
\hline Has media exposure & & $0.80(0.67,0.59)$ & & $0.91(0.75,1.11)$ \\
\hline \multicolumn{5}{|l|}{ Had mobile } \\
\hline No & & 1 & & 1 \\
\hline Yes & & $0.48(0.38,0.59)$ & & $0.60(0.48,0.76) * * *$ \\
\hline
\end{tabular}

Insurance 
Table 3 Multivariable multilevel logistic regression analysis of both individual and community-level factors associated with Home Delivery in Ethiopia, EDHS 2016 (Continued)

\begin{tabular}{|c|c|c|c|c|}
\hline \multirow{3}{*}{$\begin{array}{l}\text { Individual and community- } \\
\text { level variables }\end{array}$} & \multicolumn{4}{|l|}{ Models } \\
\hline & Null model & Model I & Model II & Model III \\
\hline & AOR $(95 \% \mathrm{Cl})$ & AOR $(95 \% \mathrm{Cl})$ & AOR $(95 \% \mathrm{Cl})$ & AOR $(95 \% \mathrm{Cl})$ \\
\hline Not insured & & 1 & & 1 \\
\hline Insured & & $0.75(0.32,1.04)$ & & $0.9(0.88,1.08)$ \\
\hline \multicolumn{5}{|l|}{ Had ANC } \\
\hline No & & 1 & & 1 \\
\hline Yes & & $0.14(0.12,0.17)$ & & $0.18(0.14,0.22)^{* * *}$ \\
\hline \multicolumn{5}{|l|}{ Birth order } \\
\hline 1 & & 1 & & 1 \\
\hline $2-4$ & & $1.76(1.34,2.30)$ & & $1.78(1.36,2.34)^{* * *}$ \\
\hline$>=5$ & & $1.81(1.24,2.67)$ & & $1.87(1.27,2.76)^{* *}$ \\
\hline \multicolumn{5}{|l|}{ Parity } \\
\hline$<=2$ & & 1 & & 1 \\
\hline $2-5$ & & $1.43(1.14,1.81)$ & & $1.37(1.08,1.74) * *$ \\
\hline$>5^{+}$ & & $1.34(0.93,1.95)$ & & $1.14(0.78,1.66)$ \\
\hline \multicolumn{5}{|l|}{ Wealth index } \\
\hline Poor & & 1 & & 1 \\
\hline Middle & & $0.81(0.65,1.02)$ & & $0.91(0.73,1.14)$ \\
\hline Richer & & $0.48(0.38,0.59)$ & & $0.78(0.61,0.99) *$ \\
\hline \multicolumn{5}{|l|}{ Residence } \\
\hline Urban & & & 1 & 1 \\
\hline Rural & & & $4.55(3.19,6.49)$ & $2.92(1.99,4.29) * * *$ \\
\hline \multicolumn{5}{|l|}{ Region } \\
\hline Addis Ababa & & & & 1 \\
\hline Tigray & & & $2.54(1.24,5.23)$ & $1.46(0.59,3.60)$ \\
\hline Afar & & & $17.24(8.06,6.89)$ & $11.03(4.29,28.41) * * *$ \\
\hline Amhara & & & $8.23(3.98,17.00)$ & $6.39(2.60,15.70) * * *$ \\
\hline Oromia & & & $7.07(3.42,14.62)$ & $3.69(1.50,9.08) * *$ \\
\hline Somali & & & $10.66(5.17,1.98)$ & $6.02(2.41,15.06) * * *$ \\
\hline Benishangul & & & $6.09(2.90,12.81)$ & $3.94(1.59,9.82) * *$ \\
\hline SNNPR & & & $5.75(2.80,11.77)$ & $3.04(1.23,7.47) *$ \\
\hline Gambla & & & $6.22(2.97,13.02)$ & $4.48(1.77,11.32) * *$ \\
\hline Harari & & & $3.59(1.69,7.64)$ & $2.68(1.04,6.89) *$ \\
\hline Dire Dawa & & & $2.73(1.28,5.84)$ & $2.01(0.77,5.20)$ \\
\hline \multicolumn{5}{|l|}{ Community ANC utilization } \\
\hline Low & & & 1 & 1 \\
\hline High & & & $0.32(0.25,0.41)$ & $0.50(0.39,0.65)^{* * *}$ \\
\hline \multicolumn{5}{|c|}{ Community Health facility distance } \\
\hline Big problem & & & 1 & 1 \\
\hline Not a big problem & & & $0.56(0.43,0.71)$ & $0.69(0.53,0.90) * *$ \\
\hline \multicolumn{5}{|l|}{ Community media exposure } \\
\hline Low & & & 1 & 1 \\
\hline High & & & $0.85(0.65,1.09)$ & $1.11(0.85,1.45)$ \\
\hline
\end{tabular}


Table 3 Multivariable multilevel logistic regression analysis of both individual and community-level factors associated with Home Delivery in Ethiopia, EDHS 2016 (Continued)

\begin{tabular}{|c|c|c|c|c|}
\hline \multirow{3}{*}{$\begin{array}{l}\text { Individual and community- } \\
\text { level variables }\end{array}$} & \multicolumn{4}{|l|}{ Models } \\
\hline & Null model & Model I & Model II & Model III \\
\hline & AOR $(95 \% \mathrm{Cl})$ & AOR $(95 \% \mathrm{Cl})$ & AOR $(95 \% \mathrm{Cl})$ & AOR $(95 \% \mathrm{Cl})$ \\
\hline \multicolumn{5}{|l|}{ Community poverty status } \\
\hline High & & & 1 & 1 \\
\hline Low & & & $0.58(0.44,0.75)$ & $0.78(0.58,1.04)$ \\
\hline \multicolumn{5}{|l|}{ Community-women education } \\
\hline Low & & & 1 & 1 \\
\hline High & & & $0.55(0.43,0.69)$ & $0.78(0.60,0.99) *$ \\
\hline \multicolumn{5}{|l|}{ Random effects } \\
\hline ICC\% & 67.32 & & & \\
\hline PCV\% & 1 & 82 & 86 & 89 \\
\hline MOR & 12.17 & 4.75 & 3.20 & 2.54 \\
\hline \multicolumn{5}{|l|}{ Model comparison } \\
\hline Log-likelihood ratio & -4749.96 & -2606.26 & -4303.85 & -2450.68 \\
\hline
\end{tabular}

families were $40 \%$ less likely to deliver at home than those who had no mobile phone. The number of mobile users and service accessibility increases in Ethiopia [36]. Women having own mobile or the family member can access ambulance on time and service for transportation to the health facility.

Furthermore, women who had at least one antenatal care (ANC) visit at the health facility was $82 \%$ less likely to deliver at home than those who had no ANC visit. Similar evidence reported from a meta-analysis in Ethiopia [37], Kenya [38], Nepal [39], and Akordet town, Eritrea [22]. Women during ANC follow up got health education about the choice of place of delivery and the benefit of health facility delivery. Therefore, women during ANC follow up will got behavioral change towards health facility delivery.

The uptake of health facility delivery decreased with high birth order and parity of $2-5$, which is consistent with the study conducted in different countries $[26,34,40,41]$. This might be the service quality given in previous births. Even if the Ethiopian health system has improved in the previous decade, still there were critical shortages of health personnel, inconsistent supplies of drugs and equipment. This could discourage women from utilizing health services in later pregnancies for delivery.

Similar to other studies evidenced $[34,40]$ that this study revealed that the poor wealth status of a household increases the likelihood of delivering at home. Even though, Ethiopia launches exempted services for delivery service and free transportation of ambulance for laboring mothers still home delivery is an issue. The possible justification might be behavioral reasons and knowledge regarding health facility delivery among the communities.

Furthermore, mothers live in Afar, Amhara, and Somali regional state of Ethiopia highest odds of giving birth at home than in Addis Ababa, which consistence another study has done Ethiopia [13]. This might be the difference in access to health services, infrastructure, and social and cultural attributes. This might be also due to better availability and accessibility of maternal health facilities around Addis Ababa as compared to other regions $[13,42]$.

This study tried to assess the spatial variation and determinants of home delivery in regions of Ethiopia. Identifying the high-risk area of home delivery in regions of Ethiopia could be used to target intervention for the home delivery reduction in high-risk areas. Therefore, identifying the spatial patterns and determinants of home delivery would help health planners and policymakers in Ethiopia.

\section{Strength and limitation of the study}

This study has strengths of having large dataset include thee EDHS survey and were nationally representative. Multilevel multivariable analysis was used to account for cluster correlations. The spatiotemporal analysis was also used for identifying hotspot areas, most likely clusters and the prediction was performed to predict unsampled/unmeasured areas in the country. However, the limitation of this study is the cross-sectional nature of the study design may affect causality. 


\section{Conclusion}

The prevalence of home delivery was 94.78, 90.05, and 73.44\% in EDHS 2005, 2011, and 2016 respectively. This study identified a spatiotemporal cluster of home delivery in Amhara and SNNPR regions consistently for Each EDHS year. Women and husband in low education, far from health facility, low wealth status, reside in rural, having a large number of children, uninsured for health, unable to accessing mobile phone, region, low community ANC utilization, low community women education, and big problem distance to any health facility were significant predictors of home delivery in Ethiopia. These results provide further insight in to identifying the true picture of home delivery Spatio-temporal clusters in the country and enable timely spatial targeting factors to alleviate home delivery. Therefore, policymakers and health planners should design an effective intervention program at the identified hot spot areas to reduce home delivery in Ethiopia.

\section{Abbreviations}

AIC: Akakian Information Criteria; AOR: Adjusted Odds Ratio; ANC: Antenatal Care; EAs: Enumeration Areas; EDHS: Ethiopian Demographic and Health Survey; LLR: Log-Likelihood Ratio; ICC: Intraclass Correlation; MOR: Median Odds Ratio; PCV: Percentage Change in Variance; SDG: Sustainable Development Goal

\section{Acknowledgments}

We, authors, acknowledge the Demographic and Health Surveys (DHS) Program funded by the U.S. Agency for International Development (USAID) for the accusation dataset.

\section{Authors' contributions}

Conception and design of the work, acquisition of data, data analysis and interpretation of data, drafting the article, revising it critically for intellectual content, and final approval of the version to be published was done by ZTT and SAT. All authors read and approved the final manuscript.

\section{Funding}

We did not receive any funds for this study.

\section{Availability of data and materials}

The data was available from the corresponding author and we can provide upon request.

\section{Ethics approval and consent to participate}

We, authors, submitted a proposal to DHS Program/ICF International Inc., and permission was confirmed from the International Review Board of Demographic and Health Surveys (DHS) program data archivists to download the dataset for this study. The data used in this study are publicly available, aggregated secondary data that hasn't any personal identifying information that can be linked to study participants. The confidentiality of data was maintained anonymously. No formal ethical approval was required in this particular study.

\section{Consent for publication}

Not applicable.

\section{Competing interests}

The authors declare that they have no competing interests.

\section{Author details}

'Department of Epidemiology and Biostatics, Institute of Public Health, College of Medicine and Health Sciences, University of Gondar, Gondar,
Ethiopia. ${ }^{2}$ Department of Public Health, College of Health Sciences, Debre Tabor University, P.O. Box. 272, Debre Tabor, Ethiopia.

Received: 17 October 2019 Accepted: 4 May 2020

Published online: 03 June 2020

\section{References}

1. United Nation. Transforming our world: the 2030 agenda for sustainable development; 2016. p. 12-4.

2. WHO, UNICEF $U$ and the WB. Trends in Maternal Mortality: 1990 to 2015, trends in maternal mortality: 1990 to 2015. Geneva: WHO; 2015.

3. WHO, UNICEF, UNFPA WBG, the UNPD. Trends in maternal mortality : 2000 to 2017. Geneva: WHO, UNICEF, UNFPA, World Bank Gr United Nations Popul Div; 2019

4. Tessema GA, Laurence CO, Melaku YA, Misganaw A, Woldie SA, Hiruye A, et al. Trends and causes of maternal mortality in Ethiopia during 1990-2013: findings from the global burden of diseases study 2013. BMC Public Health. 2017:17(1):1-8.

5. WHO. Trends in maternal mortality 1990 to 2015. Estimates developed by WHO, UNICEF, UNFPA, and The World Bank; 2015. p. 96.

6. Johnston R. The 2030 agenda for sustainable development; 2016. p. 12-4.

7. Say L, Chou D, Gemmill A, Tunçalp Ö, Moller AB, Daniels J, et al. Global causes of maternal death: a WHO systematic analysis. Lancet Glob Health. 2014;2(6):1-11.

8. Manuscript A, Europe PMC Funders Group. Global, regional, and national levels and causes of maternal mortality during 1990-2013: a systematic analysis for the Global Burden of Disease Study 2013. 2014;384(9947):9801004

9. WHO. WHO | Skilled attendants at birth. Geneva: WHO; 2018.

10. UNFPA. Trends in maternal health in Ethiopia. In: In-depth anal EDHS 20002011; 2012. p. 7

11. Central Statistical Agency (CSA) [Ethiopia] and ICF. Ethiopia demographic and health survey 2016. Addis Ababa: CSA and ICF; 2016.

12. Worku AG, Yalew AW, Afework MF. Factors affecting utilization of skilled maternal care in Northwest Ethiopia: a multilevel analysis. BMC Int Health Hum Rights. 2013;13(1):20.

13. Yebyo $\mathrm{H}$, Alemayehu $\mathrm{M}$, Kahsay $\mathrm{A}$. Why do women deliver at home? Multilevel modeling of Ethiopian national demographic and health survey data. PLoS One. 2015;10(4):1-14

14. Nigussie Teklehaymanot A, Kebede A, Hassen K. Factors associated with institutional delivery service utilization in Ethiopia. Int J Women's Health 2016;8:463.

15. Mensa M. Status of skilled birth attendance utilization and determinants among women of child-bearing age in Chencha Woreda, Gamo Gofa Zone, Southern Ethiopia, December 2016. Juniper Online J Case Stud. 2017:4(3): 248-66.

16. Hagos S, Shawano D, Assegid M, Mekonnen A, Afework MF, Ahmed S. Utilization of institutional delivery service at Wukro and Butajera districts in the Northern and South Central Ethiopia. BMC Pregnancy Childbirth. 2014; 14(1):178

17. Bedilu K, Niguse M. Delivery at home and associated factors among women in childbearing age, who gave birth in the preceding two years in Zala Woreda, southern Ethiopia. J Public Heal Epidemiol. 2017;9(6):177-88.

18. O'Sullivan D. Geographically weighted regression: the analysis of spatially varying relationships (review). Geogr Anal. 2003;35(3):272-5.

19. Kulldorff M. Theory and methods A spatial scan statistic. Commun Stat 1997;26(6 February 2013):1481-96.

20. Mayisso Rodamo K. Magnitude and determinants of utilization of skilled birth attendance among women of child-bearing age in Sidama Zone, Southeast Ethiopia. J Gynecol Obstet. 2015;3(4):69.

21. Assefa $L$, Alemayehu M, Debie A. Magnitude of institutional delivery service utilization and associated factors among women in pastoral community of awash Fentale district Afar Regional State, Ethiopia. BMC Res Notes. 2018; 11(1):4-9.

22. Gebregziabher NK, Zeray AY, Abtew YT, Kinfe TD, Abrha DT. Factors determining choice of place of delivery: analytical cross-sectional study of mothers in Akordet town, Eritrea. BMC Public Health. 2019:19(1):1-11.

23. Asefa A, Gebremedhin S, Messele T, Letamo Y, Shibru E, Alano A, et al. Mismatch between antenatal care attendance and institutional delivery in South Ethiopia: a multilevel analysis. BMJ Open. 2019;9(3):1-10. 
24. Shehu CE, Ibrahim MTO, Oche MO, Nwobodo El. Determinants of place of delivery: a comparison between an urban and a rural community in Nigeria. J Public Heal Epidemiol. 2016;8(6):91-101.

25. Firdawek E. Magnitude and determinants of antenatal and delivery service utilization in Arba Minch town, South Ethiopia. Sci J Public Heal. 2015;3(3): 339.

26. Dickson KS, Adde KS, Amu H. What influences where they give birth? Determinants of place of delivery among women in rural Ghana. Int J Reprod Med. 2016;2016:1-8.

27. Central Statistical Agency Addis Ababa El. Ethiopia demographic and health survey 2011. Addis Ababa: Central Statistical Agency; 2012.

28. Mekonnen ZA, Lerebo WT, Gebrehiwot TG, Abadura SA. Multilevel analysis of individual and community-level factors associated with institutional delivery in Ethiopia. BMC Res Notes. 2015;8(1):1-9.

29. Alemu A. Women's preference of home delivery in Wonago District, Gedeo Zone, Southern Ethiopia 2018. J Gynecol Obstet. 2019;7(3):85.

30. Habte F, Demissie M. Magnitude and factors associated with institutional delivery service utilization among childbearing mothers in Cheha district, Gurage zone, SNNPR, Ethiopia: A community based cross sectional study. BMC Pregnancy Childbirth. 2015;15(1):1-12.

31. Pradhan PMS, Bhattarai S, Paudel IS, Gaurav K, Pokharel PK. Factors contributing to antenatal care and delivery practices in village development committees of the llam district, Nepal Kathmandu. Univ Med J. 2013;11(41): 60-5.

32. Doctor HV, Nkhana-Salimu S, Abdulsalam-Anibilowo M. Health facility delivery in sub-Saharan Africa: successes, challenges, and implications for the 2030 development agenda. BMC Public Health. 2018;18(1):1-12.

33. State $R$, Ahmed AT. Determinants of institutional delivery service utilization among pastorals of Liben Zone, Somali; 2016. p. 705-12.

34. Huda TM, Chowdhury M, El Arifeen S, Dibley MJ. Individual and community level factors associated with health facility delivery: a cross sectional multilevel analysis in Bangladesh. PLoS One. 2019;14(2):1-13.

35. Pacagnella RC, Cecatti JG, Parpinelli MA, Sousa MH, Haddad SM, Costa ML, et al. Delays in receiving obstetric care and poor maternal outcomes: results from a national multicentre cross-sectional study. BMC Pregnancy Childbirth. 2014;14(1):1-15.

36. Ethio-Telecom. Teledensity in Ethiopia as of December 31, 2018. Addis Ababa: Ethio telecom; 2018.

37. Fekadu GA, Kassa GM, Berhe AK, Muche AA, Katiso NA. The effect of antenatal care on the use of institutional delivery service and postnatal care in Ethiopia: a systematic review and meta-analysis. BMC Health Serv Res. 2018;18(1):1-11.

38. Gitonga $E$, Muiruri F. Determinants of health facility delivery among women in Tharaka Nithi County, Kenya. Pan Afr Med J. 2016;25(Supp 2):9.

39. Pathak P, Shrestha S, Devkota R, Thapa B. Factors associated with the utilization of institutional delivery service among mothers. J Nepal Health Res Counc. 2018;15(3):228-34.

40. Mezmur M, Navaneetham K, Letamo G, Bariagaber H. Individual, household and contextual factors associated with skilled delivery care in Ethiopia: evidence from Ethiopian demographic and health surveys. PLoS One. 2017; 12(9):1-16.

41. Jafree SR, Zakar R, Mustafa M, Fischer F. Mothers employed in paid work and their predictors for home delivery in Pakistan. BMC Pregnancy Childbirth. 2018;18(1):1-9.

42. Adewuyi EO, Zhao Y, Auta A, Lamichhane R. Prevalence and factors associated with non-utilization of the healthcare facility for childbirth in rural and urban Nigeria: analysis of a national population-based survey. Scand J Public Health. 2017;45(6):675-82.

\section{Publisher's Note}

Springer Nature remains neutral with regard to jurisdictional claims in published maps and institutional affiliations.

Ready to submit your research? Choose BMC and benefit from:

- fast, convenient online submission

- thorough peer review by experienced researchers in your field

- rapid publication on acceptance

- support for research data, including large and complex data types

- gold Open Access which fosters wider collaboration and increased citations

- maximum visibility for your research: over $100 \mathrm{M}$ website views per year

At BMC, research is always in progress.

Learn more biomedcentral.com/submissions 